\section{References}

Berman, E.F. \& Akman, L.C. (1952) Intra-arterial infusion in treatment of shock resulting from coronary occlusion. Amer. Heart J. 43, 264.

BotTicelli, J.T., TsagaRis, T.J. \& LANGe, R.L. (1965) Mechanisms of pressor amine dependence. Amer. J. Cardiol. 16, 847.

Corday, E., Bergman, H.C. \& Kruger, H.E. (1949) Studies on coronary circulation; effect of shock on heart and its treatment. Amer. Heart J. 37, 560.

Epstein, F.H. \& Relman, A.S. (1949) Transfusion treatment of shock due to myocardial infarction. New Engl. J. Med. 241, 2889.

Estes, E.H., JR, Entman, M.L., Dixon, H.B. \& Hackel, D.B. (1966) The vascular supply of the left ventricular wall. Amer. Heart J. 71, 58.
Hellerstein, H.K., Brofman, B.L. \& Caskey, W.H. (1952) Shock accompanying myocardial infarction: treatment with pressor amines. Amer. Heart J. 44, 407.

Kurland, G.S., Weingarten, C. \& Pitt, B. (1965) The relation between the location of coronary occlusions and the occurrence of shock in acute myocardial infarction. Circulation, 31, 646.

Mitra, B. (1965) Potassium, glucose and insulin in treatment of myocardial infarction. Lancet, ii, 607.

Nixon, P.G.F., Ikram, H. \& Morton, S. (1966) Infusion of dextrose solution in cardiogenic shock. Lancet, i, 1077.

Sodi-Pallares, D. (1961) Possibility of a therapy of cellular ion integration in cardiovascular diseases. Arch. Inst. Cardiol. Mexico, 31, 577.

\title{
Discussion to the papers by J. B. L. Howell; M. W. McNicol; and P. G. F. Nixon, H. Ikram and S. Morton
}

GreEN. Dr Howell must be congratulated on giving us such a clear account of the theoretical basis of oxygen therapy and of the practical problems involved. There are, however, one or two points about his paper that I would like to raise.

With regard to the administration of oxygen, we have assessed a number of devices from the point of view of how easily one can predict the concentration of oxygen that they will deliver, whether this is appropriate in treating bronchitics, the degree of rebreathing produced and finally, but undoubtedly of great importance, how comfortable and convenient they are. We found that the patients unanimously preferred the nasal cannulae; one of the masks least liked was the Ventimask. The nasal cannulae proved equally as predictable as the Edinburgh mask and could be relied upon to give $27-40 \%$ oxygen with flows of between 1 and $4 \mathrm{l} / \mathrm{min}$, with sufficient accuracy for clinical use. It is now possible to obtain Ventimasks that deliver with incredible accuracy 24, 28 and $35 \%$ oxygen. I believe that the $24 \%$ Ventimask and a nasal cannula is all that is required for administering oxygen to bronchitics in respiratory failure, unless they need assisted ventilation. There is no need to resort to such things as head-tents, which both our patients and nurses have found very difficult to get on with.

Finally, our tendency recently has been to artificially ventilate these patients at a much earlier stage than previously. If a patient shows evidence of peripheral circulatory failure or a persistent disorder of consciousness, or if we think he is likely to become seriously hypercarbic with the simple methods I mentioned, then he is bronchoscoped and a cuffed endotracheal tube is put down under local anaesthesia. He is then ventilated for $48 \mathrm{hr}$. We have found that this approach has greatly speeded up the recovery of patients that a year ago we would have treated in a more conservative manner, and has reduced dramatically the number of patients requiring tracheostomies and long periods of ventilation.

This brings me to my final point. Dr Howell has said that there is a world of difference in the ease of treating patients, on the one hand, in units with adequate staffing and all the advantages of blood-gas analysis and artificial ventilation, and, on the other, in hospitals with inadequate nursing staff and no ancillary aids. He says that no hospital where the mixed venous $\mathrm{PCO}_{2}$ cannot be measured should treat such patients. I am sure that this must exclude a great many hospitals in our region that admit many bronchitics each season, and it seems unlikely that they will have all the necessary equipment for some time. For this reason I think there is some urgency for the measurement of the effects of anoxia and hypercarbia on the various organs of the body, so that more concrete rules of therapy can be advocated for use in less well-equipped hospitals.

ABER. I think it should be appreciated that whereas the normal arterial oxygen tension in an ambulant patient is about $80-90 \mathrm{mmHg}$, this is not true of patients without cardio-pulmonary disease, or normal subjects for that matter, who retire to bed, in whom I have seen oxygen tensions between the $70-75 \mathrm{mmHg}$ mark within $2 \mathrm{hr}$. Hence if we consider anoxia to be present when the arterial oxygen tension drops below $70 \mathrm{mmHg}$, patients with myocardial infarction do not have far to go before becoming anoxic.

Secondly, I am not convinced that the group of patients who become anoxic and in whom one cannot improve matters with oxygen administration by mask or nasal catheter, is a small one. We have found that it is quite frequent to find this type of patient in whom we have not been able to produce satisfactory arterial oxygen tensions whilst they are breathing oxygen through a nasal catheter (up to $8 \mathrm{l} / \mathrm{min}$ ) or through a polymask or M.C. mask. It is only when one introduces triggered intermittent positive pressure ventilation that the arterial oxygen rises.

ThомAs. I found the communications given by $\mathrm{Dr}$ McNicol and Dr Nixon interesting from many points of view, and provocative in some respects. The increasing attention to the subject of care and treatment of patients with acute myocardial infarction seems to be progressing along two main paths: first, the improvement of practical facilities for patient management, including the provision of intensive care units, electrocardiograph monitoring, warning systems-either electronic or humanand continuous supervision, both nursing and medical, to enable rapid handling of the more dramatic cardiac emergencies. The second main activity is the analysis of the fundamental physiology of the disease and the 
evaluation of new forms of treatment. The two papers are well suited as a basis for brief consideration of some of the problems concerned in improving the practical management of patients and developing new forms of treatment.

Dr McNicol mentions the theoretical possibility of reducing mortality after cardiac infarction by $15 \%$. Although this percentage may not sound too impressive, this is in fact a life or death issue for many thousands of patients each year in this country when it is looked at in terms of absolute numbers. It is necessary at the same time to think of practical implications. For the theoretical figure that McNicol mentions to become a reality, optimum conditions for treatment must be available in every hospital. Those of us who are fortunate enough to enjoy the advantages of working in large hospitals sometimes tend to get a one-sided view of practical medicine. For us the number of doctors for a given number of patients is high; there is no important shortage of nurses; emergency services are established routines, and, speaking comparatively, there is no shortage of money for the purchase of special equipment. In the majority of hospitals, however, there are fewer medical staff, fewer nurses and much less money available, and the establishment of services which offer true 'intensive care' with a 24-hr service, is not easy.

The complications of cardiac infarction have been discussed in detail and views on treatment were given, but another difficulty arises in that many complications such as cardiac arrhythmias, systemic hypotension, failure of the myocardium, peripheral vascular changes, respiratory and metabolic complications, are by no means fully understood with regard to their significance in each individual patient and the best management available. In units which have special facilities for investigating and analysing the many factors involved, some firm basis for assessing the whole cardiovascular problem is possible but as yet the physiological data and the relationship with the patient's illness are not sufficiently understood to allow rational treatment in many of the most seriously ill patients.

There are, therefore, financial and practical matters in association with gaps in fundamental knowledge which militate against achieving a potential $15 \%$ reduction in mortality. Dr McNicol might perhaps comment, therefore, on the essentials, which on the basis of his personal experience, offer 'the most for the least' in caring for these patients. In particular one needs advice on nursing and medical cover; is special training necessary? Should the basic equipment include electronic alarm systems or should human observation be the early warning system?

With respect to the introduction of new forms of treatment, Dr Nixon's reports are remarkable. Patients who show these physical signs he described are extremely ill and will no doubt form the 'hard core' of the potential $15 \%$ mortality reduction. In these patients, conventional treatment is usually unrewarding. For this reason, any new approach to the problem demands rigorous examination. Many patients of the type which Dr Nixon defines have a moderate or severe degree of pulmonary oedema and anuria, and consequently many clinicians are hesitant to adopt a form of therapy that essentially consists of a continuous infusion of fluid. A critical analysis of this method of treatment is therefore essential

The apparent benefit from any given intervention inf. patients with acute myocardial infarction is often very difficult to assess because of the multiplicity of factors? that may be involved. Transfusion of fluids-saline dextrose, plasma or blood-into patients with acute myocardial infarction failed to become popular whern studied 10-15 years ago because small series of patient $\vec{D}$ failed to show increased survival rates when given infusions either by the intravenous or intra-arteria $P$ routes and it was the considered opinion of some author $\overrightarrow{0}$ ities that deterioration followed infusion. Also bloodvolume measurements have not shown hypovolaemiaw except in a few patients who have been severely ill for as very long time. It would seem, therefore, that one is noto dealing with a simple problem of replenishing lost blood volume. How then does the volume of dextrose infused influence the circulation? The suggestion that distension of the ventricle enables the muscle to contract mores effectively and that stroke volume is thereby increased cannot be rejected, but neither can it be accepted in the absence of more information. Since the left ventricleo is the one most often at fault and since the left ventricle is responsible for maintaining the systemic circulation, elevation of central venous pressure has comparativelyo little relevance because changes in the left atrial pressure. would be the operative factor in this instance.

When assessing the improvement which occurred ine the energetic 76-year-old quoted, one is immediately impressed by the change in heart rate. The rate waso initially about $40 / \mathrm{min}$ and in the course of clinical improvement between 20.13 and 12.38 hours increase to about $80 / \mathrm{min}$. In our experience when such patients undergo an increase of heart rate from about 40 to $80 / \mathrm{min} \Phi$ spontaneously or as the result of the administration of drugs such as atropine, the cardiac output when measured, increases in approximate relation to the increase in heart rate unless ventricular function is extremely poor. would guess that the cardiac output increased $60-70 \%$ in this patient-and this in itself would provide a veryo good haemodynamic basis for his improvement. Whether? the ventricular rate change occurred spontaneously oroas a result of the treatment cannot be determined Perhaps Dr Nixon considered the use of cardiac pacing in this case?

While there are many difficulties in looking at these complexities in retrospect, $I$ think such a discussion is a useful pointer to the difficulties which surround evalua $-\frac{7}{2}$ tion of any treatment given to patients seriously ill with acute myocardial infarction.

GHADIALI. In the management of acute and severe cardiovascular insufficiency - 'cardiogenic shock'-after $N$ open heart surgery and during the course of valvular disease of the heart, isoprenaline has proved to be of great value not only in raising the cardiac output but also in maintaining the peripheral circulation in a reasonable state. Fifty per cent glucose has also been given intravenously and improvement in the heart action has:been noted on a few occasions. The other measures have $\frac{T}{-}$ included the use of artificial ventilation with or without $\frac{\text { + }}{\mathbb{D}}$

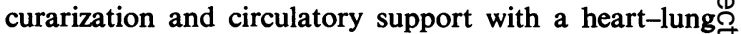
machine. I wonder whether these principles could not be applied in the management of the critically ill 'coronary' patient. 
NixON. It must be emphasized and understood that the type of patient I described did not have moderate or severe pulmonary oedema. I believe that further experience will confirm our present finding of low left atrial pressure in such a patient, in whom elevation of the venous pressure appears to result from 'venous constriction', rather than from 'congestive heart failure'. Oedema fluid may flow by gravity into the chest from the remainder of the body if the patients are nursed supine on a soft mattress with the legs raised, but this is not pulmonary oedema caused by acute elevation of the pulmonary venous and left atrial hydrostatic pressures.

The studies made 10-15 years ago which Dr Thomas mentioned did not show better survival rates in patients treated by infusion, but often the fluid was given injudiciously, and was not controlled by close observation of the arterial and central venous pressures. In some series a good recovery rate from 'shock' was obtained, but the patients succumbed later from dysrhythmia or pulmonary embolism in ways that may nowadays be prevented by intensive-care and observation. I have already pointed out that the finding of a normal blood volume does not exclude the newly-injured heart from having a need for an enlarged blood volume. The concept and the treatment are not so remarkable to those practiced in the care of patients subjected to acute cardiac injury at open-heart surgery.

With regard to the heart-rate, I believe that the increase in this 76-year-old man was secondary to an improvement in the heart action and peripheral circulation. Two of the cases that we have reported presented with complete heart-block in addition to the 'shock', and pacemaking control of the rate did nothing to improve the latter condition. Before we began to use dextrose infusion we saw many patients die from 'shock' despite adequate electrical control of the heart-rate; the use of artificial ventilation, and the exhibition of pressor amines with or without digitalis.

CARLO. The use of carbohydrates in the treatment of myocardial infarction is not new. The use of glucose, potassium and insulin in the treatment of myocardial infarction was described by Laborit in France as early as 1954. Sodi-Pallares, who is a well-known authority, endorsed and studied the method. The term 'repolarizing solution' is not original to Sodi-Pallares either, but was coined by Laborit. Many of the practical aspects of this form of therapy can be found in a recent publication Electrolytes and Cardiovascular Disease, edited by Karger in Basel under the auspices of Dr Bajusz of Montreal.

\section{References}

LABORIT, H. (1958) Intérêt majeur du glucose hypertonique en réanimation. Presse méd. 66, 444.

LABORIT, H. (1963) Le traitement des insuffisances cardiovasculaires et de l'infarctus du myocarde par l'association insuline, glucose hypertonique, sels de potassium. Presse méd. 71, 1.

LABORIT, H. \& HuguenaRd, P. (1956) Echanges ioniques, tonus musculaire, metabolisme cellulaire, Bilan d'une étude expérimentale et aperçus thérapeutiques. Presse méd. 64, 605.

Laborit, H. \& Huguenard, P. (1956) Aspects biologiques de la réanimation cardiaque et vasculaire. Applications pratiques. J. Chir. (Paris), 72, 681.

The other articles to which I referred are published in: Electrolytes and Cardiovascular Diseases, PhysiologyPathology-Therapy Vol. 2, Clinical Aspects (Ed. by Eörs Bajusz), University of Montreal (Canada), 1966. Karger, Basel.

NiEPER, H.A. \& Blumberger, K. Electrolyte Transport Therapy of Cardiovascular Diseases, Experimental and Clinical Basis, pp. 141-173.

Sodi-Pallares, D., Bisteni, A., Medrano, G.A., Micheli, A., Ponce de Leon, J., Calva, E., Fishleder, B.L., Testelli, M.R. \& Miller, B.L. The Polarizing Treatment in Cardiovascular Conditions. Experimental Basis and Clinical Applications, pp. 198-238.

LABORIT, H. New Physiological Concepts of Cardiovascular Functions: Therapeutic Consequences, pp. 239-259.

QUESTION FROM THE FLOOR. Dr McNicol, what staffing structure exists in your department and what monitoring do you consider essential to treating coronaries?

McNicol. We are working on two general wards with fifty beds staffed by two consultants, two registrars and two house physicians with one additional registrar engaged in full-time research work. Our nursing staff at the moment is $60 \%$ of our establishment and at night we frequently have only three nurses between two wards. Nursing staff was not adequate to permit detailed observation of any patient and special nurses were available only with difficulty. The annual turnover of the wards was 1200 cases of whom 120 had myocardial infarction. Mortality in 1963 was $34 \%$ and it had fallen in 1965 to $22 \%$. Resuscitation was attempted by the same cardiac arrest team on the same number of patients on other wards but no patients were successfully resuscitated elsewhere in the hospital. The only monitoring possible was of ECG wave form and heart rate and there were many difficulties about the use of the monitors. They were used mainly as red lights at the top of the bed indicating that the patient was in need of special attention rather than as a proper scientific monitoring device.

ABER. May I interpose a quick comment regarding the use of oral propranolol in patients who are having frequent ventricular extrasystoles? We have seen several patients who develop considerable hypotension (a drop of $30-40 \mathrm{mmHg}$ ) after oral administration of 20 $\mathrm{mg}$ of propranolol. This can be rapidly reversed by the administration of atropine and may occur repeatedly during the first $24-48 \mathrm{hr}$ of treatment. It would seem, therefore, that it is not only intravenous propranolol that one should be very careful with, and that more observations need to be made regarding the potential dangers of even small doses of oral propranolol under these circumstances.

GREEN. I would like now to discuss a subject that Dr Howell briefly touched upon-tissue oxygenation. I, of course, agree when he says that measurements of the cardiac output, arterial oxygen tension and total body oxygen uptake do not tell us whether or not there is tissue anoxia. He advocates instead the measurement of the whole body lactate-pyruvate ratio as the method of choice in deciding whether or not there is significant tissue anoxia. I think here he is making a similar error because there may not be a great disturbance of the $\mathbf{L} / \mathbf{P}$ ratio of the whole body although profound tissue anoxia is present in some vital organ. Conversely a 
disturbance in the total $\mathbf{L} / \mathbf{P}$ ratio may not necessarily mean that vital organs are significantly anoxic for we know that adjustments that take place in the distribution of the circulating blood during anoxia favour some tissues more than others. I believe that until we have studied the regional blood flows to vital organs such as the brain, the heart and the liver in profound anoxia, determined how the total flow is redistributed and correlated this information with an assessment of their function, we shall not be able to say what is a safe level of $\mathrm{Po}_{2}$. Local disturbances of the $\mathrm{L} / \mathrm{P}$ ratio may be of further help. Aber has done a study of renal blood flow in patients with severe obstructive airways disease and found that at $\mathrm{PaO}_{2} \mathrm{~s}$ as low as $23 \mathrm{mmHg}$ renal function may be unimpaired, and we, at Birmingham, intend to make measurements of cerebral blood flow and coronary flow in these same sort of patients this coming winter. such damage is not yet defined but both McNicol and $\stackrel{\bar{\complement}}{2}$ Nixon administered oxygen in high concentrations to $C$ patients in cardiogenic shock assuming that tissue $\vec{F}$ hypoxia is the basic cause of the pathology. Howell has $\stackrel{\oplus}{+}$ supported the view of McNicol and Nixon that such cell injury manifests itself as a metabolic acidosis. Howell $\bar{\sigma}$ has also suggested that changes in lactic and pyruvic $\frac{\bar{\omega}}{\sigma}$ acids and their ratio in arterial blood may be the best $\overparen{\Phi}$ available objective index of tissue hypoxia and Aber $\stackrel{\varrho}{\Omega}$ and Green have discussed the significance of this ratio. We have conducted studies in both human patients and $\vec{\circ}$ animals under conditions of reduced blood flow, with a view to determining whether changes in arterial lactate $\vec{\omega}$ and pyruvate are an index of tissue hypoxia and McConn $\stackrel{\odot}{\circ}$ will show that while changes in lactate or in pyruvatec do not reflect the circulatory conditions, changes in the 3 . lactate-pyruvate ratio were most marked when the blood $\vec{\omega}$

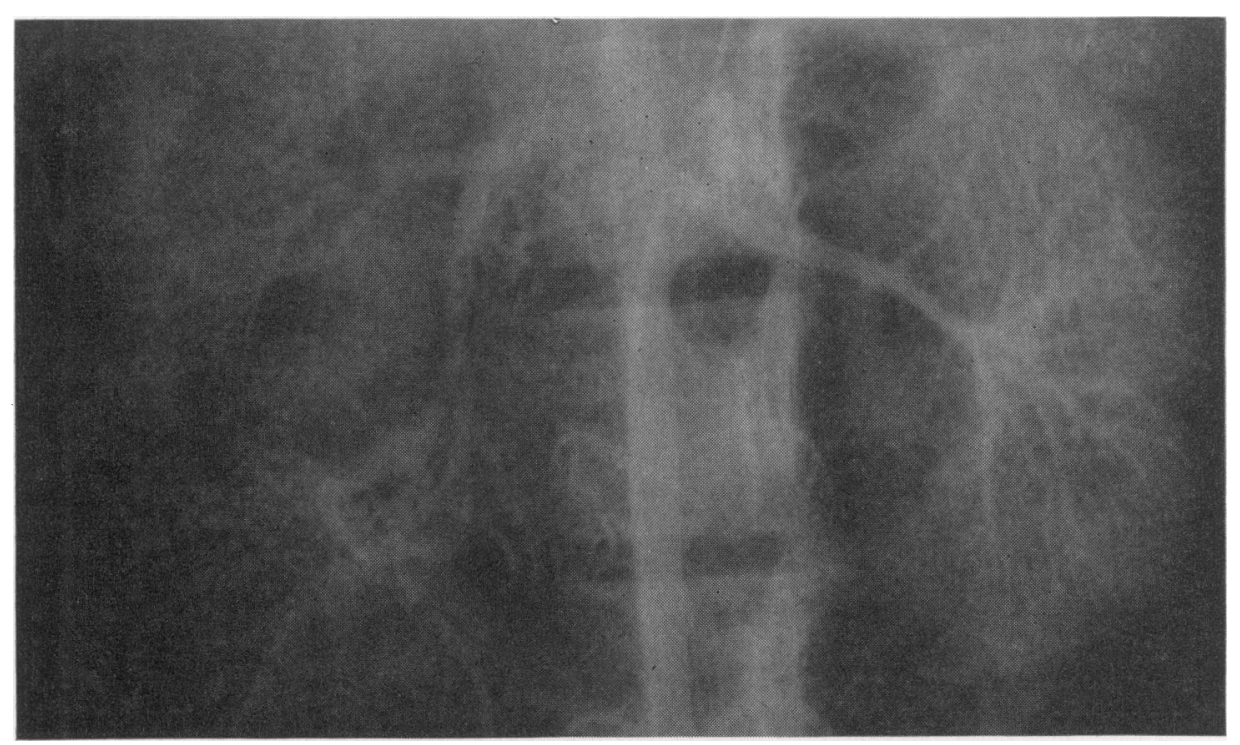

FIG. A1. A renal angiogram obtained $1.5 \mathrm{sec}$ after the intra-aortic injection of thorotrast into a healthy young adult monkey.

ABER. I agree with Dr Green that one must have doubts regarding the significance of the total lactatepyruvate ratio abnormalities of mixed venous or arterial blood. It seems to me that disturbances in regional perfusion which occur following myocardial infarction can produce considerable abnormalities of organ function without producing much, if any, disturbance in the total lactate-pyruvate ratio. For example, we have demonstrated by using modified bromsulphthalein tests and lactic dehydrogenase iso-enzyme studies, that marked disturbances in hepatic function follow myocardial infarction (Aber et al., 1966, Lancet, i, 1391). Our initial observations on renal performance likewise suggest that it is not all it should be, so that there certainly appears to be a real need for studying individual organ performance in this group of patients rather than merely considering the body as a whole.

Ambiavagar. Drs Howell, McNicol and Nixon have all touched on the metabolic disorders in shock which are generally attributed to cellular injury. The cause of pressure was very low and the arterial oxygen tension was below $200 \mathrm{mmHg}$. My objective now is to describe 음 the conditions of blood flow during which these biochemical observations were made.

Fig. A1 shows a renal angiogram obtained $1.5 \mathrm{sec}$ after the intra-aortic injection of thorotrast into a healthy $\mathrm{N}$ young adult monkey. The points to note in this normal $\mathrm{N}$ angiogram are the size of the renal shadow, where the $\mathrm{N}$ capillary phase is seen to be complete, and the calibre $\omega$ of the arteries.

Fig. A2 (a) and (b) are nephrograms from the same 0 monkey during normovolaemic hypotension and $a \frac{\bar{\Phi}}{\Phi}$ systolic pressure of $40 \mathrm{mmHg}$ induced by IPPV with $\stackrel{\oplus}{+}$ halothane, and show that circulation was slowed but $\square$ not otherwise markedly interfered with during normovo- $\overline{0}$ laemic hypotension. These experiments were carried out $\frac{\vec{D}}{\mathbb{D}}$ with halothane-oxygen or halothane-air mixtures and $\frac{O}{\mathbb{D}}$ although there were significant differences in the bio- $\varrho$ chemical changes under these two conditions, the angiograms were similar. 

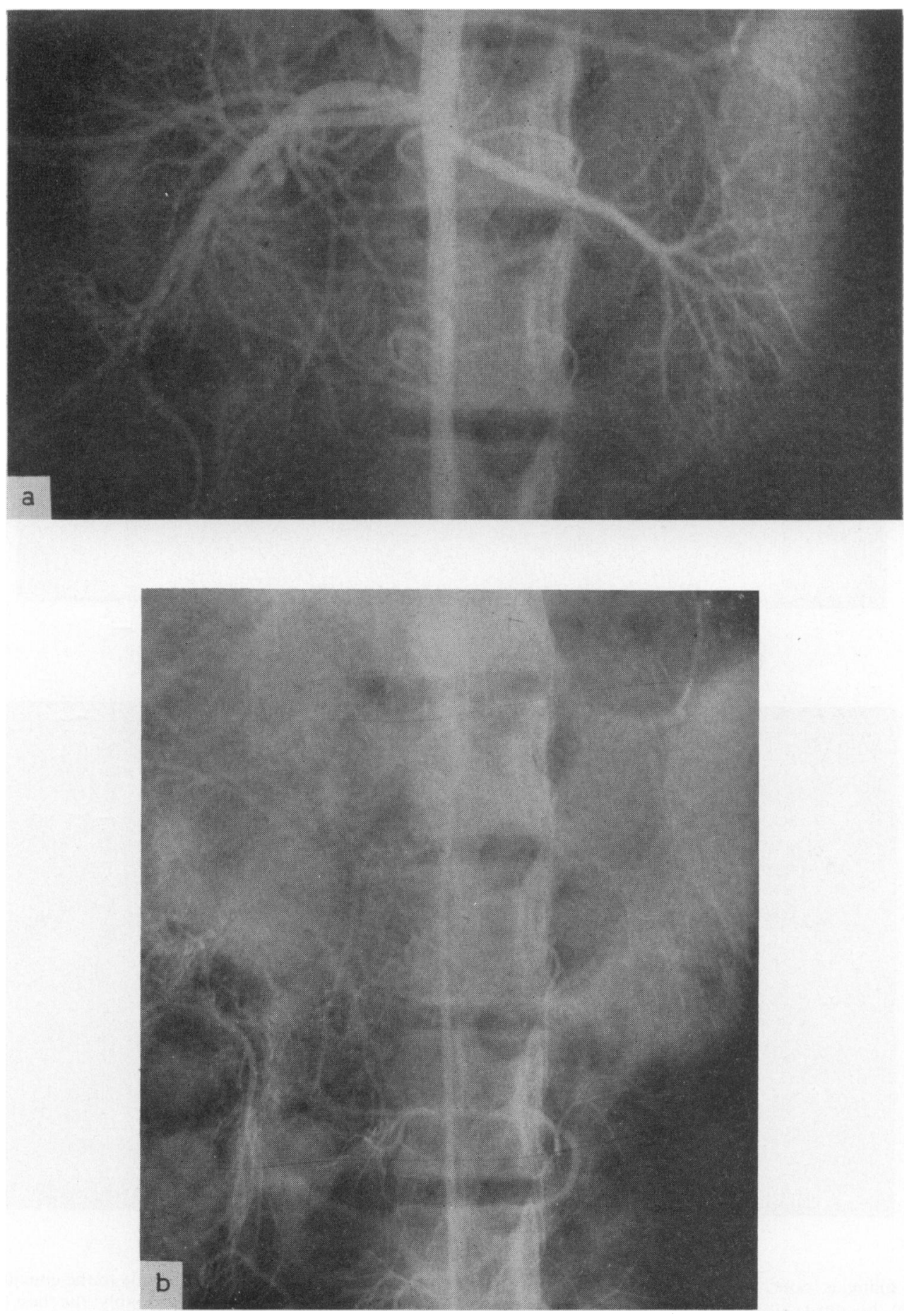

FIG. A2. (a) and (b) are nephrograms from the same monkey during normovolaemic hypotension and a systolic pressure of $40 \mathrm{mmHg}$ induced by IPPV with halothane. (a) obtained $1.5 \mathrm{sec}$ after injection of thorotrast (cf. Fig. A1) and (b) 3 sec after injection. 
Fig. A3 is a nephrogram from a healthy adult monkey after the systolic blood pressure had been lowered to $40 \mathrm{mmHg}$ by arteriotomy. The differences between the circulation here and in the previous figures is immediately apparent. Extreme vasoconstriction is present and
McConN. Friedman \& Barborka (1941) first suggested $\frac{3}{\mathbb{\Phi}}$ that the increases in lactate-pyruvate $(L / P)$ ratio found $c$. during exercise might be used as an index of tissue hypoxia and other workers have found evidence in $\stackrel{5}{+}$ support of this theory. Studies in clinical situationso

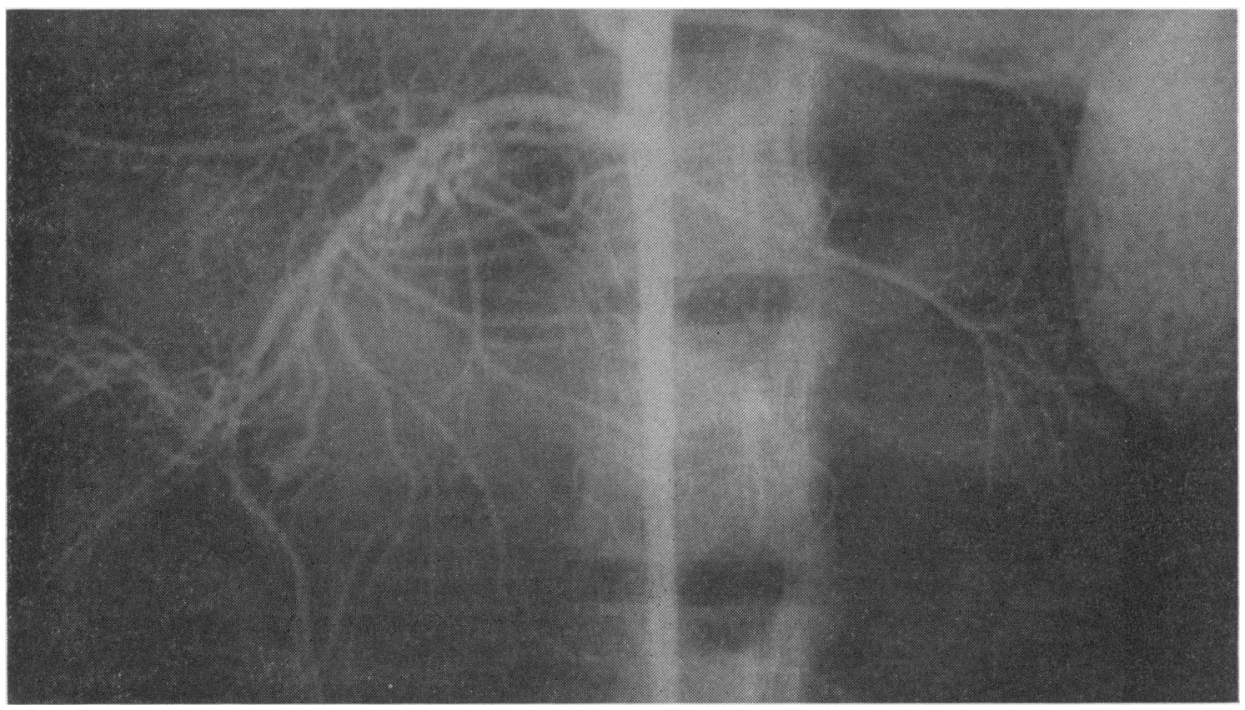

Fig. A3. Nephrogram from a healthy adult monkey after the systolic blood pressure had been lowered to $40 \mathrm{mmHg}$ by arteriotomy.

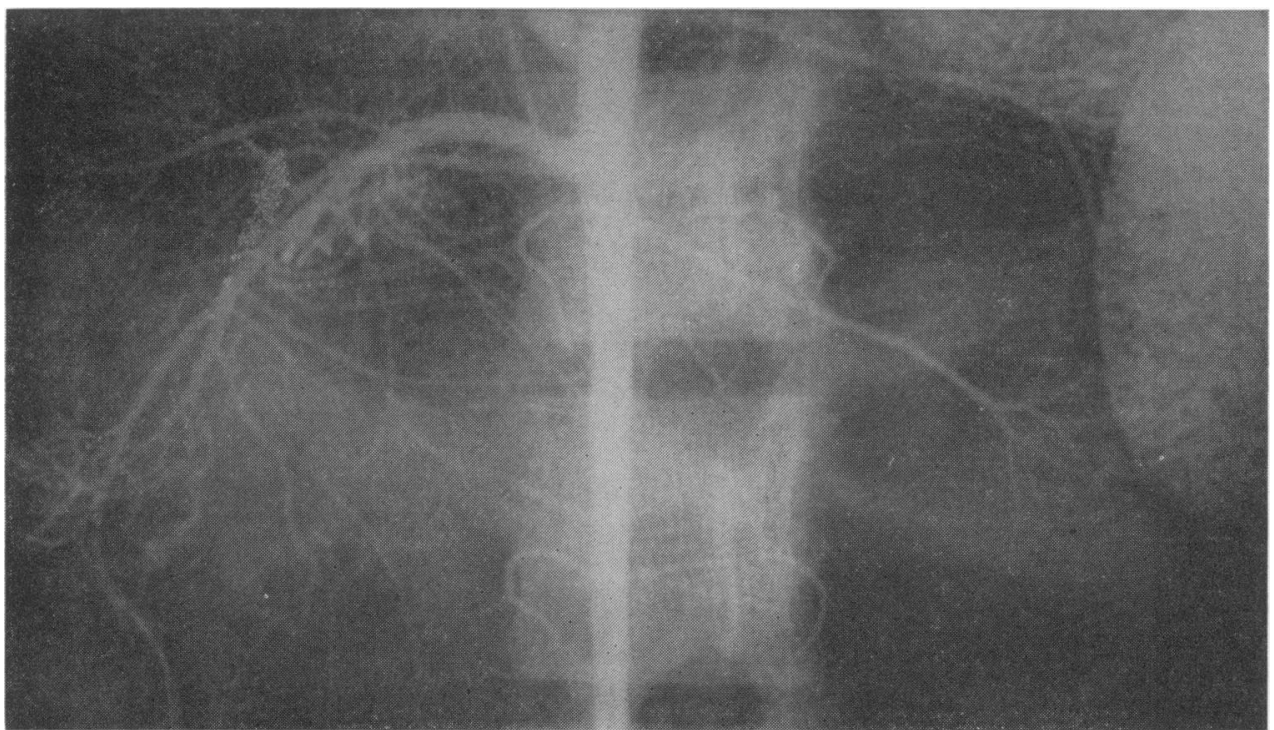

Fig. A4.

cortical filling is poor. Halothane administered to the animal at this stage caused a further fall in blood pressure but no vasodilatation was seen (Fig. A4), whereas following phenoxybenzamine (Fig. A5) vasodilatation and increased renal perfusion were found despite a fall in blood pressure to $20 \mathrm{mmHg}$. during the past 4 years have led me to the conclusion that $\frac{0}{0}$ changes in $L / P$ ratios are probably the best available $\frac{\mathbb{D}}{\mathbb{D}}$ index of tissue hypoxia, but in describing these studies $\frac{?}{\mathscr{T}}$

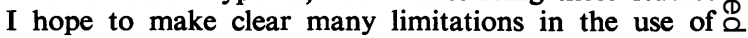
$\Delta \mathrm{L} / \mathrm{P} \%$ as an index of tissue hypoxia. $\Delta \mathrm{L} / \mathbf{P} \%$ was measured in four different clinical and 
experimental situations and the results were correlated with other measurements which are relevant to tissue oxygenation such as the arterial oxygen tension and tissue oxygen tension and I will now describe these changes in the context of the situations in which they were measured. and because of this wide range, each patient was used as his own control and changes in the ratio, expressed as changes of the control value were termed $\Delta \mathrm{L} / \mathrm{P} \%$.

First, two groups of patients were studied: (a) those with a clinically normal circulation during anaesthesia with nitrous oxide, oxygen, curare and IPPV, and (b)

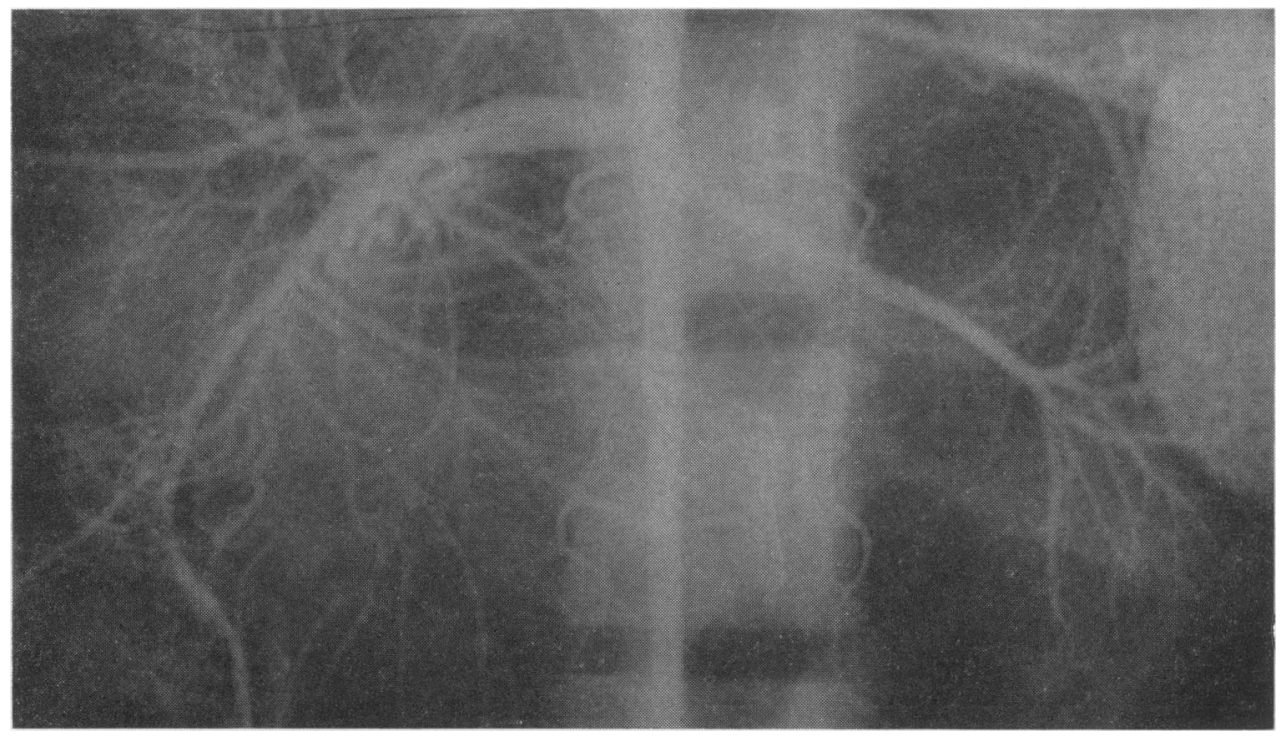

Fig. A5.

The lactate and pyruvate concentrations were measured in the arterial blood of nineteen fasting patients who were at bed rest and awaiting surgery. In these control conditions, the ratio $\mathrm{L} / \mathrm{P}$ varied from $9 \cdot 23$ to $21 \cdot 1$ (Table A1)

\section{TABLE A1}

Lactate and pyruvate concentrations and ratio in arterial blood in patients awaiting surgery under control conditions of fasting and bedrest ( $n=$ no. of patients)

\begin{tabular}{lccc}
\hline & $\begin{array}{c}\text { Lactate } \\
(\mathrm{mM} / \mathrm{l})\end{array}$ & $\begin{array}{c}\text { Pyruvate } \\
(\mathrm{mM} / \mathrm{l})\end{array}$ & L/P \\
\hline Mean $(n)$ & $0.944(19)$ & $0.0624(19)$ & 14.47 \\
Range & $0.497-1.40$ & $0.036-0.105$ & $9.23-21 \cdot 10$ \\
\hline
\end{tabular}

those undergoing cardiac surgery with cardio-pulmonary bypass in conditions where the circulation was likely to be inadequate, e.g. during ventricular fibrillation at the end of bypass and after aortic occlusion. The mean $\Delta \mathrm{L} / \mathrm{P} \%$ was 13.7 and the maximum was 33 in group (a) (Table A2) but in group (b) there was a ten-fold increase in the ratio.

$\Delta \mathrm{L} / \mathrm{P} \%$ was next measured in ten patients in whom hypotension was induced by halothane- $\mathrm{O}_{2}$ and IPPV. The systolic blood pressure was lowered to $40-45 \mathrm{mmHg}$ for the duration of surgery which was from 5 to $9 \mathrm{hr}$. In three patients, mean $\Delta \mathrm{L} / \mathrm{P} \%$ was +60 to +312 and two out of these three developed renal failure post-operatively. In the other seven the $\Delta \mathrm{L} / \mathrm{P} \%$ was less than 33 . Fig. A6 shows the relationship between $\mathrm{PaO}_{2}$ and $\Delta \mathrm{L} / \mathrm{P} \%$ in this group of patients during hypotension. When the

TABLE A2

Evaluation of the lactate-pyruvate ratio in patients during anaesthesia

\begin{tabular}{|c|c|c|c|c|}
\hline & $\begin{array}{l}\text { Lactate } \\
(\mathrm{mM} / \mathrm{l})\end{array}$ & $\begin{array}{l}\text { Pyruvate } \\
\text { (mM/l) }\end{array}$ & $\mathbf{L} / \mathbf{P}$ & $\Delta \mathrm{L} / \mathrm{P} \%$ \\
\hline \multicolumn{5}{|c|}{ During normal tissue perfusion-a standard anaesthetic procedure } \\
\hline $\begin{array}{l}\text { Mean }(n) \\
\text { Range }\end{array}$ & $\begin{array}{l}0.826(15) \\
0.589-0.977\end{array}$ & $\begin{array}{l}0.071(15) \\
0.050-0.115\end{array}$ & $\begin{array}{r}15 \cdot 3(15) \\
8 \cdot 3-19 \cdot 8\end{array}$ & $\begin{array}{c}+13 \cdot 7 \\
-27 \cdot 4-+33 \cdot 0\end{array}$ \\
\hline \multicolumn{5}{|c|}{ After reduced tissue perfusion during cardiopulmonary bypass } \\
\hline $\begin{array}{l}\text { Mean ( } n) \\
\text { Range }\end{array}$ & $\begin{array}{l}6 \cdot 30(9) \\
2 \cdot 91-11.7\end{array}$ & $\begin{array}{l}0.166(9) \\
0.067-0.275\end{array}$ & $\begin{array}{l}41 \cdot 8(9) \\
20 \cdot 2-85 \cdot 1\end{array}$ & $\begin{array}{c}+14.2 \\
+40.0-+303.0\end{array}$ \\
\hline
\end{tabular}


$\mathrm{PaO}_{2}$ was less than $250 \mathrm{mmHg}$ large increases in the ratio occurred, and these values are from the patients who developed renal failure. These low $\mathrm{PaO}_{2}$ values occurred although all patients were ventilated with

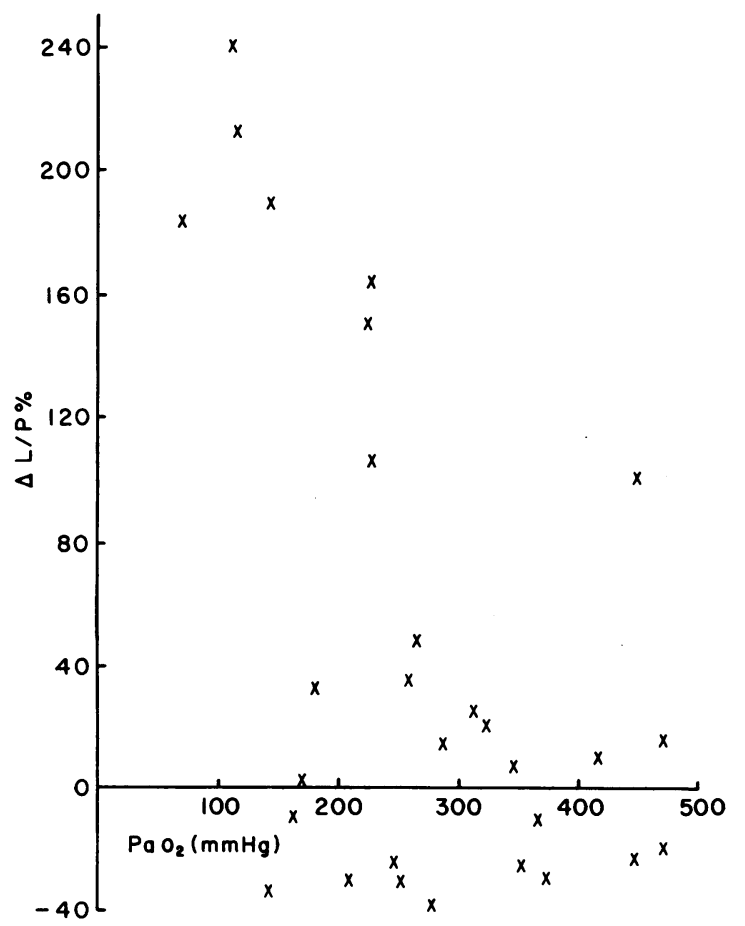

FIG. A6. Relationship between $\mathrm{PaO}_{2}$ and changes in the lactate-pyruvate ratio $(\Delta \mathrm{L} / \mathrm{P} \%)$ during induced hypotension.

$98 \% \mathrm{O}_{2} ; \mathrm{PaO}_{2}$ values were found to vary from 71 to 500 $\mathrm{mmHg}$ despite a standard inspired mixture of $98 \%$ oxygen and $2 \%$ halothane. During hypotension a metabolic acidosis was found in all patients but the base deficit showed no correlation with the concentrations of lactate or $\Delta \mathrm{L} / \mathrm{P} \%$.
The study was repeated in a group of monkeys who were subjected to a period of normovolaemic hypotension $ᄃ$ using halothane and IPPV with air or $\mathrm{O}_{2}$ as a carrier $\overrightarrow{\stackrel{\vec{m}}{*}}$ gas. Several hours' hypotension was followed by a? recovery period of $2-3 \mathrm{hr}$ and then hypovolaemic hypotension was produced by arteriotomy. The changes $\frac{\overline{-}}{\mathrm{n}}$ in lactate and pyruvate concentrations and ratio during $\frac{}{5}$ normovolaemic and hypovolaemic hypotension are $\mathbb{\complement}^{\mathbb{2}}$ shown in Table A3. These results confirmed the earliero observation of the importance of $\mathrm{PaO}_{2}$ levels during normovolaemic hypotension. The ratio increased by only $50 \%$ in animals ventilated with halothane- $\mathrm{O}_{2}=$ (mean $\mathrm{PaO}_{2}=394 \mathrm{mmHg}$ ) compared with $185 \%$ in those ventilated with halothane-air (mean $\mathrm{PaO}_{2}=96 \frac{\mathrm{s}}{\circ}$ $\mathrm{mmHg}$ ). In contrast, during hypovolaemic hypotensiono changes in the ratio were similar whether the animal was 3 . breathing air or $\mathrm{O}_{2}$ and in fact the increase was greater $\mathrm{c}_{\mathrm{\omega}}^{+}$ in the animal breathing $\mathrm{O}_{2}$. This would suggest that high. $\mathrm{PaO}_{2}$ levels do not greatly influence tissue oxygenation ${ }_{\infty}$ if hypotension is associated with extreme vasoconstriction.

The oxygen tension of skeletal muscle was recordedo continuously during these experiments and renal angio-? grams were taken at each stage of the experiment (p. 218). $\vec{\nabla}$

The $\mathrm{Po}_{2}$ for muscle was $23-33 \mathrm{mmHg}$ under controlo conditions and there was a direct correlation between =$\mathrm{PaO}_{2}$ and tissue $\mathrm{PO}_{2}$. During normovolaemic hypotension $\vec{\theta}$ the tissue $\mathrm{PO}_{2}$ fell progressively, reaching $10-20 \%$ of the control value after several hours. It did, however, show small increases with rises in blood pressure pro--O duced by changing the halothane concentration or the intrathoracic pressure. During hypovolaemic hypoten-o sion, however, the tissue $\mathrm{Po}_{2}$ fell, almost immediatelyo after the animal was bled, to $10-20 \%$ of the control 2 value and remained at this value throughout. Fig. $A 7 \stackrel{\Rightarrow}{\Rightarrow}$ shows tissue $\mathrm{Po}_{2}$ in one animal in the group and serves to illustrate these changes.

All clinically available methods of estimating the adequacy of tissue oxygenation were employed simultaneously in this animal study and each of these will beo critically discussed.

(a) Blood pressure: It is widely accepted that changes: in blood pressure do not indicate changes in blood flow

TABLE A3

Lactate and pyruvate concentrations and ratios in monkeys during (a) control period, (b) normovolaemic hypotension and (c) hypovolaemic hypotension

\begin{tabular}{|c|c|c|c|c|c|}
\hline \multirow[b]{2}{*}{ Inspired mixture: } & \multirow{2}{*}{ Control } & \multicolumn{2}{|c|}{ Normovolaemic hypotension } & \multicolumn{2}{|c|}{ Hypovolaemic hypotension } \\
\hline & & Halothane $/ \mathrm{O}_{2}$ & Halothane/air & $\mathbf{O}_{2}$ & Air \\
\hline $\begin{array}{l}\text { Lactate (mM/l) } \\
\text { Mean }(n) \\
\text { Range }\end{array}$ & $\begin{array}{l}1.217(6) \\
0.939-2.98\end{array}$ & $\begin{array}{l}3 \cdot 157(7) \\
2 \cdot 53-4 \cdot 78\end{array}$ & $\begin{array}{l}3.460(11) \\
0.933-8.09\end{array}$ & $\begin{array}{l}4 \cdot 34(5) \\
2 \cdot 12-7 \cdot 55\end{array}$ & $\begin{array}{l}10 \cdot 95(6) \\
2 \cdot 63-19 \cdot 7\end{array}$ \\
\hline $\begin{array}{l}\text { Pyruvate }(\mathrm{mm} / \mathrm{l}) \\
\text { Mean }(n) \\
\text { Range }\end{array}$ & $\begin{array}{l}0 \cdot 110(6) \\
0.086-0.204\end{array}$ & $\begin{array}{l}0 \cdot 184(7) \\
0 \cdot 109-0.257\end{array}$ & $\begin{array}{l}0.131(11) \\
0.043-0.247\end{array}$ & $\begin{array}{l}0 \cdot 139(4) \\
0 \cdot 176-0.235\end{array}$ & $\begin{array}{l}0.347 \\
0.170-0.500\end{array}$ \\
\hline $\begin{array}{l}\text { L/P } \\
\text { Mean } \\
\text { Range }\end{array}$ & $\begin{array}{l}12 \cdot 60(6) \\
5 \cdot 90-19 \cdot 2\end{array}$ & $\begin{array}{l}18 \cdot 49(7) \\
9 \cdot 85-27 \cdot 2\end{array}$ & $\begin{array}{l}28 \cdot 51(11) \\
18 \cdot 2-49 \cdot 2\end{array}$ & $\begin{array}{c}25 \cdot 42(4) \\
9 \cdot 8-27 \cdot 2\end{array}$ & $\begin{array}{l}32 \cdot 27(6) \\
18 \cdot 2-37 \cdot 1\end{array}$ \\
\hline $\begin{array}{l}\Delta \mathrm{L} / \mathrm{P}^{\circ} / \\
\text { Mean } \\
\text { Range }\end{array}$ & & $\begin{array}{l}+49.9(7) \\
+6.6-36.7\end{array}$ & $\begin{array}{l}+184 \cdot 6(8) \\
+33 \cdot 6-+410\end{array}$ & $\begin{array}{l}+163 \cdot 6(4) \\
+141-+186\end{array}$ & $\begin{array}{l}+137 \cdot 0(6) \\
+81 \cdot 6-+132\end{array}$ \\
\hline
\end{tabular}


and pressure is only measured so frequently in the sort of clinical circumstances I am describing because its measurement is so easy.

(b) Metabolic acidosis: Tissue hypoxia is not the only cause of this. It is important, however, to correct any severe metabolic acidosis when treating hypotension. Fig. A8 shows persistent hypotension in an animal with (d) The tissue oxygen electrode is influenced by many factors, e.g. blood pressure, flow and oxygen content and tension, and only indicates the conditions at the site of measurement. Thus it has a place in experimental conditions for studying responses in individual organs.

(e) Lactate-pyruvate ratio: If the ratio is measured in arterial blood, the changes may be regarded as reflecting

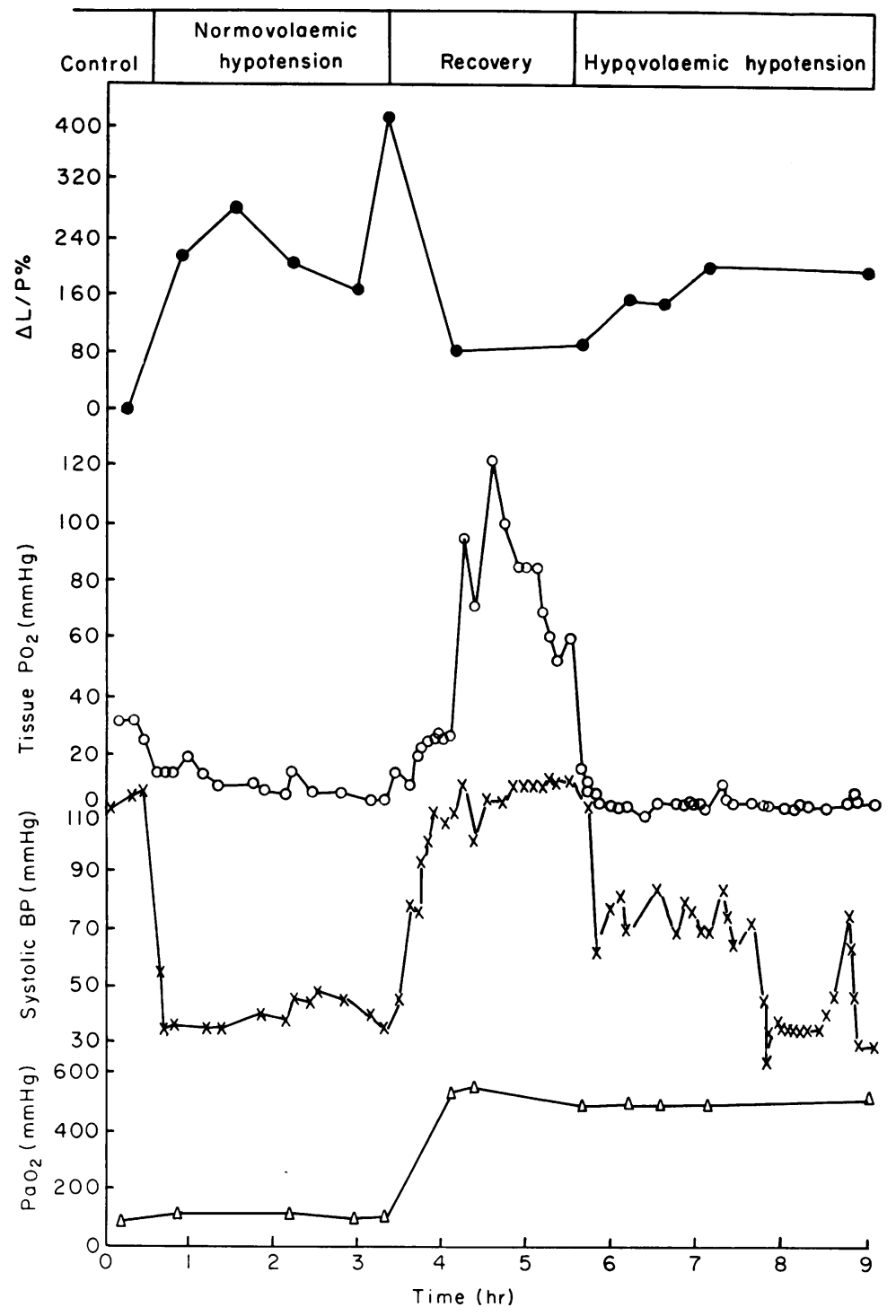

Fig. A7. Tissue $\mathrm{Po}_{2}$, systolic $\mathrm{BP}$ and $\mathrm{PaO}_{2}$ values and $\Delta \mathrm{L} / \mathrm{P} \%$ in a monkey during normovolaemic and hypovolaemic hypotension.

a base deficit of $-22 \mathrm{mEq} / \mathrm{l}$. Hypertension responded dramatically to intravenous sodium bicarbonate infusions.

(c) $\mathrm{PaO}_{2}$ : During profound normovolaemic hypotension, values of $\mathrm{PaO}_{2}$ in excess of $250 \mathrm{mmHg}$ were necessary for adequate tissue oxygenation whereas in hypovolaemic hypotension tissue hypoxia occurred despite $\mathrm{PaO}_{2}$ values of $500 \mathrm{mmHg}$. changes in the whole animal, but it is not possible to determine which part or parts of the body are hypoxic unless venous blood draining the particular organ is analysed.

Since each patient is his own control, clinical studies must be retrospective. If a patient with chronic obstructive lung disease showed a progressive fall in the 
ratio during treatment this would suggest an improvement in tissue oxygenation and one could perhaps draw similar conclusions in cardiogenic shock, but unfortunately we have not made sufficient measurements to assess the value of oxygen enrichment of the inspired atmosphere or of the effects of vasodilators and transfusions on tissue oxygenation in cardiogenic shock. hypotension with its accompanying intense vasocon- $\stackrel{\mathbb{Q}}{2}$ striction the metabolic products we measured were not $c$ washed out of the tissues and that under these conditions $\overrightarrow{\overline{\vec{A}}}$ the ratio may be misleadingly low.

Finally, it is worth noting that large increases in $\mathrm{L} / \mathrm{P}$ ratio associated with short periods of circulatory failure as in group (b) (Table A2) were not associated with

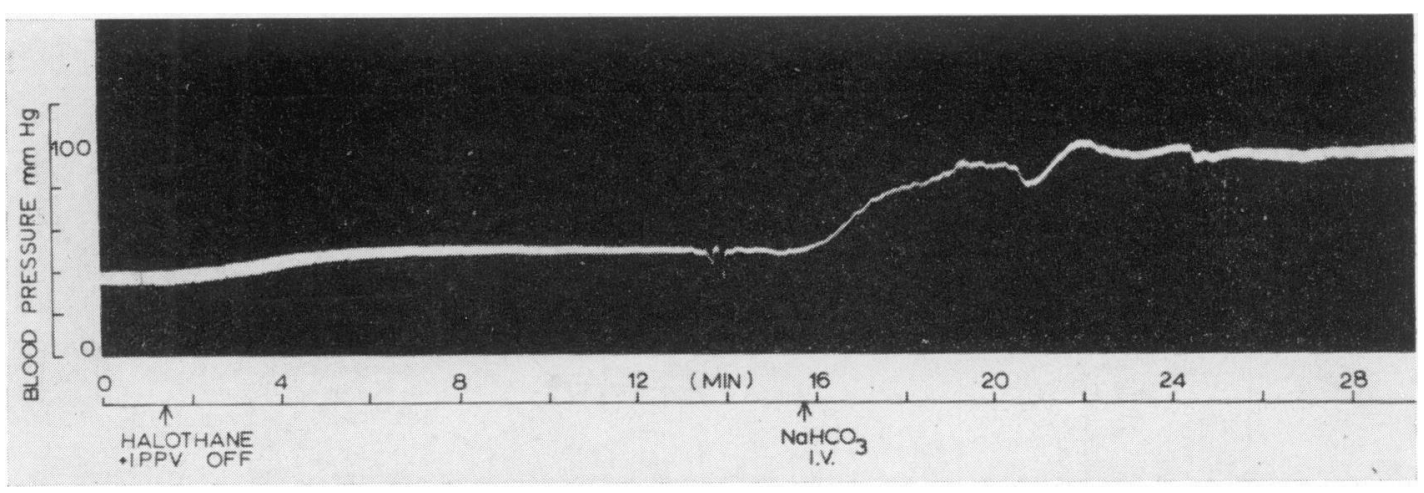

FIG. A8. Response of arterial BP to correction of a severe metabolic acidosis which recurred in a monkey after a period of hypotension induced by halothane air and IPPV. Nineteen milli-equivalents of $\mathrm{NaHCO}_{3}(19 \mathrm{ml} \mathrm{w} / \mathrm{v}, 8 \cdot 4 \%)$ was given i.v. to correct a base deficit of $22 \mathrm{mEq} / \mathrm{l}$.

When the ratio is used, it must be carefully interpreted against the clinical background. The need for this caution may be illustrated by reference to Fig. A7 which shows that the increase in the ratio during normovolaemic hypotension was almost twice that during hypovolaemic hypotension. This does not mean that tissue hypoxia was twice as severe during normovolaemic hypotension, but rather that during hypovolaemic clinical ill-effects but that similar increases occurring over prolonged periods as in the hypotensive anaesthesia group, were associated with renal failure.

\section{Reference}

Friedman, T.E. \& BARBORKA, C.J. (1941) The significance of the ratio lactic to pyruvic acid in the blood after exercise. J. biol. Chem. 141, 993. 


\section{Errata}

Postgraduate Medical Journal (1967) Vol. 43, No. 498, 'Intensive Therapy.'

Please nOte the following:

Page 222. The last sentence of the first paragraph should read: 'During hypotension a metabolic acidosis was found in all patients but the base deficit showed no correlation with the concentrations of lactate. There was statistical correlation with $\Delta \mathrm{L} / \mathrm{P} \%$.'

Page 223. The last sentence of paragraph (b) should read: 'Hypotension responded ....'

Page 254. The legend to Fig. A7 should read:

-Pressure-volume loops from the second case when breathing spontaneously $\left(A_{1}\right)$ and during controlled IPPV (B). A normal loop (A) is shown for comparison.

Page 268. The formula in the second column should read:

$$
\frac{\mathrm{Q}}{\mathrm{Qs}} \cdots \frac{1}{1+\frac{(\mathrm{A}-\mathrm{V} \text { diff }) \times 330}{\mathrm{PAO}_{2}-\mathrm{PaO}_{2}}}
$$




\section{Errata}

Postgraduate Medical Journal (1967) Vol. 43, No: 498, 'Intensive Therapy.'

Please note the following:

Page 222. The last sentence of the first paragraph should read: 'During hypotension a metabolic acidosis was found in all patients but the base deficit showed no correlation with the concentrations of lactate. There was statistical correlation with $\Delta \mathrm{L} / \mathrm{P} \%$,'

Page 223. The last sentence of paragraph (b) should read:

'Hypotension responded ....'

Page 254. The legend to Fig. A7 should read:

'Pressure-volume loops from the second case when breathing spontaneously $\left(\mathrm{A}_{1}\right)$ and during controlled IPPV (B). A normal loop (A) is shown for comparison.

Page 268. The formula in the second column should read:

$$
\frac{\mathrm{Q}}{\mathrm{Qs}}=\frac{1}{1+\frac{(\mathrm{A}-\mathrm{V} \text { diff }) \times 330}{\mathrm{PAO}_{2}-\mathrm{PaO}_{2}}}
$$

